ORIGINAL ARTICLE

\title{
Randomised controlled trial and cost consequences study comparing initial physiotherapy assessment and management with routine practice for selected patients in an accident and emergency department of an acute hospital
}

\author{
B Richardson, L Shepstone, F Poland, M Mugford, B Finlayson, N Clemence
}

Emerg Med J 2005;22:87-92. doi: 10.1136/emj.2003.012294

See end of article for authors' affiliations

\section{Correspondence to:} Dr B Richardson, School of Allied Health Professions (formerly Occupational Therapy and Physiotherapy), University of East Anglia, Norwich NR4 7TJ, UK;

b.richardson@uea.ac.uk

Accepted for publication 23 June 2004

\begin{abstract}
Objective: The Department of Health is reviewing the effectiveness of accident and emergency (A\&E) departments. This study aimed to compare health and economic effects of physiotherapy initial assessment and management with routine practice in an A\&E department.

Methods: Randomised controlled trial and cost and consequences study. Patients presenting at A\&E were eligible if suspected at triage to have soft tissue injury without fracture. The efficacy end point was "days to return to usual activities". Secondary end points included patient satisfaction with their care and further health outcomes and cost data.

Results: 766 of 844 (915) patients were randomised. The median days before return to usual activities (available for $73 \%$ of those randomised) was greater in the physiotherapist group (41 days compared with 28.5 days; hazard ratio $0.85 \mathrm{p}=0.071)$. The physiotherapy group expressed greater satisfaction with their A\&E care (on a scale of 1 to 5 , median was 4.2 compared with $4.0, p<0.001$ ), were more likely to be given advice and reassurance, and more likely to be provided with aids and appliances. Costs were the same between the two arms.

Conclusion: There is evidence that physiotherapy leads to a prolonged time before patients return to usual activities. This study shows no clear danger from physiotherapy intervention and long term outcomes may be different but given these findings, a best estimate is that introducing physiotherapist assessment will increase costs to the health service and society. Routine care should continue be provided unless there is some reason why it is not feasible to do so and an alternative must be found.
\end{abstract}

$\mathrm{T}$ he Department of Health ${ }^{1}$ is reviewing the effectiveness of accident and emergency (A\&E) services. Proposed solutions have included streaming of patients to the most appropriate care and breaking down the barriers between professional groups. ${ }^{2}$

Recent studies have examined the scope for professions not usually employed in A\&E departments to assess and plan the needs of some patients. Some musculoskeletal conditions presenting in A\&E are suitable for physiotherapy assessment but may be missed..$^{3-5}$ Early physiotherapy involvement in A\&E may be positively beneficial clinically with potential to reduce referrals to review clinics and other services ${ }^{6}$ and Bakewell (unpublished data). To date, no randomised controlled study has been undertaken to investigate this.

This study aimed to compare the clinical effectiveness and costs of two alternative assessment routes for patients presenting with musculoskeletal problems to an A\&E department. The objectives were to establish whether, on a range of outcomes, there was any clinically significant difference between assessment and management by physiotherapists and routine assessment and management of musculoskeletal problems and to assess the comparative costs of the alternative approaches to care.

\section{METHODS \\ Design}

A randomised controlled trial and economic evaluation was conducted. The trial was designed as a non-inferiority trial in which the null hypothesis is of inferiority of outcome for one group. It would be assumed that the physiotherapy intervention was inferior and therefore not to be recommended unless there was positive evidence to the contrary. Unlike the traditional approach, this type of trial does not demand superiority but that the new intervention is at least as good. Thus we were supposing that effectiveness may not be improved but that the new intervention is no worse and comes at a benefit in cost. A small pilot study of 15 patients who would have been eligible for the study was carried out before the main study to establish variation in times taken to return to usual activities. Using the "time to return to usual activities" as the primary outcome measure for return to function, the following assumptions were made: "time to return to usual activity" was considered equivalent if the mean times for each arm were within one week; the standard deviation of this measure was four weeks. Non-inferiority would be claimed if the lower limit of a 95\% confidence interval for the difference in mean time to return to usual activities did not fall below one week in favour of the control group-that is, above the difference considered to be the minimum clinical relevant difference. Fixing the probability of type I and type II errors at 0.025 and 0.1 respectively, with an estimated standard deviation of four weeks and allowing for $10 \%$ loss to follow up gave 375 subjects to be recruited in each arm.

The study took place between October 2001 and December 2002 in a large district hospital A\&E department serving a wide catchment area. The hospital A\&E department moved to a new site during the recruitment period. Two superintendent III grade physiotherapists, were deployed to work day time shifts in A\&E for this project. Patients, admitted during the periods when the physiotherapists were on duty, were 


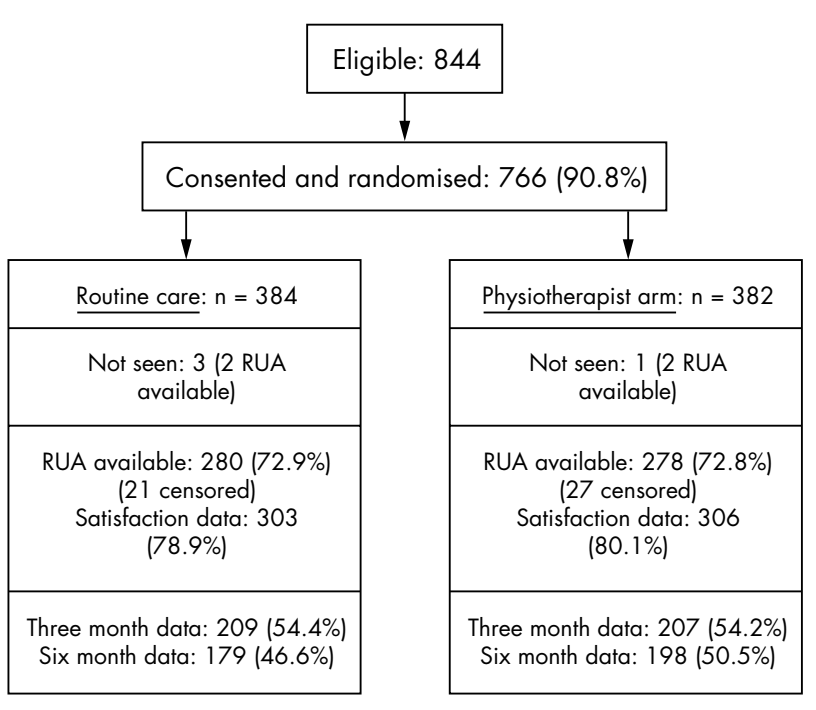

Figure 1 Patient flow.

assessed at triage as having relevant musculoskeletal conditions. A randomisation list was blocked in block length of 6 . Group assignment was provided in sealed envelopes either to the intervention group, receiving initial assessment and management by a physiotherapist, or to the control group who received routine $\mathrm{A} \& \mathrm{E}$ assessment and management as determined by the doctor/emergency nurse practitioner. The triage nurse assigned patients into one of five groups currently used to prioritise patient care $^{78}$ ranging from Tl (emergency requiring immediate specialist medical assessment) to T5 (non-urgent). Patients diagnosed as suffering from musculoskeletal conditions in categories T3, 4, or 5 were eligible for the trial. This included: acute strains and sprains of spine, shoulder, elbows, wrists, hands, hips, knees, ankles, feet, soft tissue injuries, cervical, thoracic and lumbar whiplash injury, torticollis, rotator cuff injuries. Patients were excluded from the trial if they were triaged to categories 1 or 2, or had infections, open wounds, eye problems, foreign bodies, poisonings, were under 18 years of age, had spinalneurological injuries, suspected fractures or dislocations, or conditions that required immediate pain relief or presented outside physiotherapists' normal working hours. Eligible patients were invited to join the trial. Those who consented were assigned to one arm of the study by the triage nurse, via block randomisation in sealed opaque envelopes. The design of this study carefully preserved the integrity of the waiting list, and all patient notes remained at the same point in the waiting pile so as not to unduly disadvantage those patients in other triage grades, those who did not join the study, or those patients who were not allocated to the physiotherapist arm of the trial. The trial physiotherapists were able to request radiographs as necessary. Prescriptions for analgesia required by the physiotherapists were made via the medical staff in line with current practice. Baseline clinical and demographic measurements were taken after patient consent, before randomisation, by a trials coordinator blind to the triage allocation. These comprised a set of self completion questionnaires to provide secondary outcome measures of patient satisfaction, quality of life, self reported return to usual activity, self reported function, and pain levels. Scores included: EuroQoL for quality of life, ${ }^{9}$ which provided a weighted health index (range 1 to-0.59) and a self rated "thermometer" (range 0 to 100) to assess health status (higher scores denoting greater wellbeing); the health assessment questionnaire (range 0 to 3, lower scores indicating better physical functioning), ${ }^{10}$ a visual analogue scale for pain levels (range 0 to 100, lower scores indicating less pain). ${ }^{11}$ Measures were repeated at three months and six months from randomisation using a postal questionnaire. Intensive efforts were made to ensure maximum response at each stage of follow up. Early responses were entered into a lottery for a small sum of money. Reminders with further questionnaires were sent to those who did not respond at three and six weeks for each measure and telephone follow up was attempted thereafter. Patients used an "events diary $^{\prime \prime 2}$ to record their use of health services and a pre-paid postcard to report the point of returning to usual activity. An additional outcome measure of patient satisfaction was made, after assessment and before management, using five questions scored on a five point Likert scale drawn from Goldstein's instrument. ${ }^{13}$

The economic evaluation was designed to compare costs and consequences for the two policies of care from health service provider, purchaser, and patient perspective. Data were collected on use of health and social services, at initial treatment and at follow up. Level of use of health and social services by patients and personal costs was collected using a self completed questionnaire developed by the researchers. ${ }^{14}{ }^{15}$ Patients completed the questionnaire at three months and six months using the events diary as an aide memoire. There were three main resource categories: health and social care in the acute hospital and community, personal out of pocket expenses, and lost production to society. Unit costs for resources used were based on available sources and from local health service administrators. Costs are given at 2001/ 2002 prices, adjusted using the NHS pay and price inflation index. ${ }^{16}$

\section{Ethics approval}

The study was approved by the district ethics committee and the research governance committee. All participants gave their written informed consent.

\section{Analysis}

Analysis was based on the intention to treat principle-that is, participants were analysed according to the group to which they were randomised rather than the service they

\begin{tabular}{|c|c|c|}
\hline & $\begin{array}{l}\text { Doctor } \\
\text { ( } \mathrm{n}=384)\end{array}$ & $\begin{array}{l}\text { Physiotherapist } \\
\text { ( } \mathrm{n}=382)\end{array}$ \\
\hline \multicolumn{3}{|l|}{ Age (y) } \\
\hline Mean (SD) & $40.0(16.4)$ & $38.7(16.1)$ \\
\hline Range & 18 to 84 & 18 to 90 \\
\hline \multicolumn{3}{|l|}{ Sex, number (\%) } \\
\hline Male & $211(55.0)$ & $232(60.7)$ \\
\hline Female & $173(45.0)$ & $150(39.3)$ \\
\hline \multicolumn{3}{|l|}{ Main activity, number (\%) } \\
\hline Employed/self employed & $282(73.4)$ & $272(71.2)$ \\
\hline Retired & $45(11.7)$ & $45(11.8)$ \\
\hline Housework & $23(6.0)$ & $21(5.5)$ \\
\hline Student & $17(4.4)$ & $26(6.8)$ \\
\hline Seeking work & $8(2.1)$ & $6(1.6)$ \\
\hline Other & $7(1.8)$ & $5(1.3)$ \\
\hline Missing* & $2(0.5)$ & $7(1.8)$ \\
\hline \multicolumn{3}{|l|}{$\begin{array}{l}\text { Education beyond minimum } \\
\text { leaving age, number (\%) }\end{array}$} \\
\hline Yes & $208(54.2)$ & $213(55.8)$ \\
\hline No & $172(44.8)$ & $165(43.2)$ \\
\hline Missing* & $4(1.0)$ & $4(1.0)$ \\
\hline \multicolumn{3}{|l|}{$\begin{array}{l}\text { Experienced serious illness } \\
\text { yourself, number (\%) }\end{array}$} \\
\hline Yes & $63(16.4)$ & $66(17.3)$ \\
\hline No & $280(72.9)$ & $267(69.9)$ \\
\hline Missing* & 41 (10.7) & 49 (12.8) \\
\hline
\end{tabular}


actually received. It was intended to analyse the primary outcome as normally distributed, with inferences based upon the mean, using a $t$ test and associated confidence intervals (the latter to assess non-inferiority). However, the distribution was extremely right skewed and for a number of patients was right censored (that is, by a certain date the participants were known to still not have returned to usual activities). "Time to event" statistical techniques are commonly used methods for analysing censored, right skewed data, therefore, it was decided to use the median value and to use a log-rank test and a confidence interval based upon the difference in median times. ${ }^{17}$ Inference for secondary outcomes was based upon the median (using a Wilcoxon-Mann-Whitney test) as the distributions of the variables did not appear appropriately modelled by a normal distribution. Confidence intervals were based upon the median difference. ${ }^{17}$

The distribution of costs was highly skewed. However, following recent recommendations, ${ }^{18}$ the differences in costs were expressed as means. Inferences were drawn based upon bootstrapped confidence intervals constructed from resampling the data 1000 times. Sensitivity of the cost results was planned to consider the robustness of the cost effectiveness results for particular subgroups of patients such as injury type, age, severity of injury, and assumptions about costs. In the event that the outcomes were equivalent, the economic study would be a cost minimisation analysis.

\section{RESULTS}

Altogether 844 patients were eligible for the study. A total of $766(91 \%)$ agreed to participate and were randomised to either arm (fig l). Three patients in the routine care arm and one in the physiotherapy arm left A\&E before receiving any treatment. For one of these the date of return to usual activities was unknown. Thirty five $(9.2 \%)$ randomised to the physiotherapy arm were diagnosed with fracture after initial assessment therefore received routine care although staying within their allocated group and therefore analysed as randomised (fig 1).

The date of return to usual activities was returned by 280 (21 censored) and 278 (27 censored) subjects, in the routine care and physiotherapy arms respectively (about $73 \%$ in each arm). Data on satisfaction with treatment were available for

\begin{tabular}{|c|c|c|}
\hline & $\begin{array}{l}\text { Routine care } \\
(n=384)\end{array}$ & $\begin{array}{l}\text { Physiotherapist } \\
(n=382)\end{array}$ \\
\hline \multicolumn{3}{|l|}{ Type of injury } \\
\hline Sports injury & $63(16.4)$ & $76(19.9)$ \\
\hline Trip or fall & $175(45.6)$ & $169(44.2)$ \\
\hline Assault & $9(2.3)$ & $7(1.8)$ \\
\hline RTA & $42(10.9)$ & $21(5.5)$ \\
\hline Other & $95(24.7)$ & $109(28.5)$ \\
\hline \multicolumn{3}{|l|}{$\begin{array}{l}\text { Time of injury before arrival } \\
\text { (h) }\end{array}$} \\
\hline 0 to 5 & $133(34.6)$ & $132(34.6)$ \\
\hline 6 to 11 & $19(5.0)$ & $13(3.4)$ \\
\hline 12 to 23 & $98(25.5)$ & $107(28.0)$ \\
\hline 24 to 47 & $43(11.2)$ & $39(10.2)$ \\
\hline \multirow{2}{*}{\multicolumn{3}{|c|}{ Site of injury }} \\
\hline & & \\
\hline Head and neck & $27(7.0)$ & $22(5.8)$ \\
\hline Shoulder, scapula/clavicle & $30(7.8)$ & $28(7.3)$ \\
\hline Upper limb & $120(31.3)$ & $110(28.8)$ \\
\hline Thoracic spine and ribs & $8(2.0)$ & $7(1.8)$ \\
\hline Lumbar/sacral spine & $14(3.6)$ & $21(5.5)$ \\
\hline Pelvis, buttocks, and hips & $5(1.3)$ & $6(1.6)$ \\
\hline Lower limb & $192(50.0)$ & $206(53.9)$ \\
\hline \multicolumn{3}{|l|}{ Self rated pain score } \\
\hline Mean (SD) & $56.1(22.6)$ & $55.4(21.9)$ \\
\hline Range & 0 to 100 & 1 to 100 \\
\hline
\end{tabular}

Table 3 Treatments received, by randomisation group

\begin{tabular}{|c|c|c|}
\hline & $\begin{array}{l}\text { Doctor } \\
\text { ( } n=384)\end{array}$ & $\begin{array}{l}\text { Physiotherapist } \\
\text { ( }=382 \text { ) }\end{array}$ \\
\hline \multicolumn{3}{|l|}{ Treatment $^{\star}$ number (\%) } \\
\hline Advice/reassurance & $232(60.4)$ & $337(88.2)$ \\
\hline Discharge GP with information & $22(5.7)$ & $4(0.1)$ \\
\hline Discharge GP with plan & $18(4.7)$ & $17(4.5)$ \\
\hline Referral to A\&E doctor & 0 & $31(8.1)$ \\
\hline $\begin{array}{l}\text { Prescription/advise for NSAIDs/ } \\
\text { analgesia }\end{array}$ & $97(25.3)$ & $23(6.0)$ \\
\hline $\begin{array}{l}\text { Referral for orthopaedic } \\
\text { assessment }\end{array}$ & $9(2.3)$ & $9(2.4)$ \\
\hline Referral to review clinic & $34(8.9)$ & $39(10.2)$ \\
\hline One off physiotherapy & 0 & $5(1.3)$ \\
\hline Referral for physiotherapy & $8(2.1)$ & $47(12.3)$ \\
\hline Plaster room & $26(6.8)$ & $24(6.3)$ \\
\hline Referral to other specialty & $3(0.8)$ & $3(0.8)$ \\
\hline Futura splint & $16(4.2)$ & $22(5.8)$ \\
\hline Tubigrip & $84(21.9)$ & $125(32.7)$ \\
\hline Soft collar & $2(0.5)$ & $4(1.0)$ \\
\hline Crutches & $28(7.3)$ & $81(21.2)$ \\
\hline Sling & $19(4.9)$ & $38(9.9)$ \\
\hline Collar and cuff & $6(1.5)$ & $5(1.3)$ \\
\hline Thumb spica & $4(1.0)$ & $13(3.4)$ \\
\hline Fracture clinic referral & $57(14.8)$ & $60(15.7)$ \\
\hline
\end{tabular}

280 and 278 respectively (roughly $80 \%$ in each arm). Additional follow up information was returned by 209 and 207 patients (about 54\% of each arm) at three months, and by 179 and 193 (about 48\% of each arm) at six months.

The two groups were similar at baseline (table 1) and presented with similar injuries (table 2). With respect to treatment (table 3) patients in the physiotherapist arm were more likely to be provided with advice and given reassurance; prescriptions and advice for non-steroidal anti-inflammatory drugs/analgesia were lower; and patients were more likely to be given aids and appliances.

The median time for return to usual activities was greater in the physiotherapist arm than the routine care arm by 12.5 days (95\% CI: 0.4 to 25.6 days), which was near significance at the $5 \%$ level $(p=0.071, \log$-rank test $)$ (table 4). There was little difference between the two arms with respect to time to return to work, with a median of seven and eight days for the routine care and physiotherapist arms respectively (95\% CI:-3.0 to 1.0 days), which was not significant ( $\mathrm{p}=0.402$, Wilcoxon-Mann-Whitney test).

A statistically significant difference was found for each of the questions on satisfaction with care and for the average score of all five questions (table 4). In the routine treatment arm $74 \%$ expressed satisfaction with services compared with $89 \%$ in the physiotherapy arm (difference $=15 \%, 95 \%$ CI: $9 \%$ to $21 \%, \mathrm{p}<0.0001$ ). These proportions differed by age but not sex: in the younger age group (below 40 years old) $69 \%$ and $89 \%$ expressed satisfaction in the routine and physiotherapy arms respectively, compared with $80 \%$ and $89 \%$ in the older age group.

At three months there was little difference between the two groups with respect to the EuroQol or self reported pain scale. There was a significant difference between the two groups with respect to HAQ scores ( $p=0.047$, WilcoxonMann-Whitney test) with lower scores in the routine care arm. At six months there were no significant, or near significant differences between the HAQ scores, self reported pain scores, or EuroQol (table 5).

\section{Economic results}

A\&E service costs did not differ significantly between the groups (difference in mean costs shows a reduction of $£ 1.33$ $95 \%$ CI $-£ 1.96$ to $+£ 4.49$ ) (table 6 ). Total health sector costs 
Table 4 Efficacy analysis, by randomisation group

\begin{tabular}{|c|c|c|c|c|}
\hline & $\begin{array}{l}\text { Routine care } \\
(n=384)\end{array}$ & $\begin{array}{l}\text { Physiotherapist } \\
\text { (n=382) }\end{array}$ & Significance $^{*}$ & $95 \% \mathrm{Cl} \dagger$ \\
\hline \multicolumn{5}{|c|}{$\begin{array}{l}\text { Time to return to usual activities } \\
\text { (days) }\end{array}$} \\
\hline Number (number censored) & $280(21)$ & $278(27)$ & \multirow{3}{*}{$p=0.071$} & \multirow{3}{*}{0.41 to 22.0} \\
\hline Median (IQR) & $28.5(48.0)$ & $41.0(56.0)$ & & \\
\hline Range & 0 to 257.0 & 0 to 321.0 & & \\
\hline Number & 146 & 150 & \multirow{3}{*}{$p=0.403$} & \multirow{3}{*}{-3.0 to 1.0} \\
\hline Median (IQR) & $7.0(23.0)$ & $8.0(33.0)$ & & \\
\hline Range & 0 to 197.0 & 0 to 169.0 & & \\
\hline \multicolumn{5}{|l|}{ Average score } \\
\hline Number & 303 & 306 & \multirow{2}{*}{$p<0.001$} & \multirow{2}{*}{4.0 to -2.0} \\
\hline Median (IQR) & $4.0(1.0)$ & $4.2(0.8)$ & & \\
\hline
\end{tabular}

were not statistically significantly different, but were higher in the physiotherapy arm. Social services costs were negligible in both arms.

Although overall costs are not different, there are some differences in use of service patterns. There were differences in treatments such as prescriptions (higher in the routine arm), referral to other professionals, and ordering of equipment (higher in the physiotherapy arm). This is reflected in the differences in hospital and community health costs shown in table 6 . The different length of time taken to return to usual activities may affect the amount of extra help paid for and the ability to return to paid work. However, return to paid work was not significantly different between the two arms of the trial, and therefore lost production costs are not significantly different.

Total reported costs were dominated by A\&E department costs to which salary costs are a contributor. Changing the rate of pay for physiotherapists from superintendent III to senior l would reduce mean total A\&E costs in the physiotherapy arm to $£ 92.24$.

\section{DISCUSSION}

A randomised controlled trial and cost consequence study was carried out with a sample of patients presenting at A\&E with soft tissue injury without fracture, with the primary outcome measure "time taken to return to usual activities". There is weak evidence that physiotherapist assessment and management leads to a prolonged time before patient's return to normal activities.

The demographic characteristics of the two groups at study baseline were broadly similar as were baseline data on

Table 5 Quality of life indicators at baseline by randomisation group

\begin{tabular}{|c|c|c|}
\hline & $\begin{array}{l}\text { Doctor } \\
(n=384)\end{array}$ & $\begin{array}{l}\text { Physiotherapist } \\
\text { ( } n=382 \text { ) }\end{array}$ \\
\hline \multicolumn{3}{|l|}{ HAQ disability index, $(n=755)$} \\
\hline Mean (SD) & $0.22(0.43)$ & $0.29(0.54)$ \\
\hline Range & 0 to 2.38 & 0 to 2.75 \\
\hline \multicolumn{3}{|l|}{$\begin{array}{l}\text { Self rated health score } \\
\text { (thermometer), }(n=754)\end{array}$} \\
\hline Mean (SD) & $77.7(17.8)$ & $74.7(18.8)$ \\
\hline Range & 19 to 100 & 20 to 100 \\
\hline \multicolumn{3}{|c|}{ Self rated pain score, $(n=760)$} \\
\hline Mean (SD) & $56.1(22.6)$ & $55.4(21.9)$ \\
\hline Range & 0 to 100 & 1 to 100 \\
\hline \multicolumn{3}{|l|}{ EQ-5D index score, $(n=697)^{*}$} \\
\hline Mean (SD) & $0.47(0.3)$ & $0.45(0.3)$ \\
\hline Range & -0.59 to 1.0 & -0.43 to 1.0 \\
\hline
\end{tabular}

patient's presenting injury with the exception of clinical diagnosis. Patients randomised to the physiotherapist arm were more likely to be categorised to inflammation, cellulitis, effusion, bursitis, tendonitis, tenosynovitis. This is likely to reflect a difference in diagnostic style of physiotherapists and doctors rather than disparity in injury type.

We were unable to gain ethical approval to collect data from those patients who were eligible and asked to participate but declined. The response rate for the three and six month follow up measures, despite a rigorous reminder system, were disappointing. This should be considered within the context of the characteristics of this acute patient population. Many fall into a young, mobile group of patients who change jobs and home addresses or embark on international travel without leaving follow up contacts. In addition several subjects were many miles away from home at the point of injury, and on their return to home this study may not have retained their interest.

Return to usual activities took longer for physiotherapy patients although the statistical evidence is weak $(p=0.07)$. However, it is important to remember that the study was set up as a non-inferiority study and there is, under our definition, no evidence of non-inferiority-that is, no evidence to suggest that, with respect to the primary outcome chosen, physiotherapists are equivalent to, or better than, routine care. The physiotherapists may have shown overcaution in this new setting, in the short term, ${ }^{19}{ }^{20}$ and in this study design the physiotherapists worked at less pressure than other A\&E staff, allowing more time for consultation and providing further cautionary advice. From those responses received, patients also took longer to return to work but not significantly. The inclusion of production loss in health economic evaluation is controversial. ${ }^{21} 22$ In the UK, health technology advice by the National Institute of Clinical Excellence does not include this aspect, however, it can be an important aspect of social cost. How production loss should be measured is also controversial, and many have rejected the valuation of paid working time because it fails to count unpaid productive activity (such as voluntary work, parenting, housekeeping, or caring for people with disabilities). We should therefore be cautious about concluding that more time lost from paid work (as observed in this study) is an overall social loss (although it would be reasonable to suppose that people who are signed off sick from work are not fit to work unpaid either). Levels of recurrence and repeated injury were only measured within a six month follow up period, which may be too short an interval to ascertain fully the incidence of repeated treatment and work absence associated with some musculoskeletal conditions with a known high incidence of recurrent injury, for example low back pain. ${ }^{23}$ However, there is a loss to the formal 
Table 6 Summary of costs by treatment group ( $£$ price year 2001/2)

\begin{tabular}{|c|c|c|c|c|}
\hline & $\begin{array}{l}\text { Routine care } \\
(\mathrm{n}=384)\end{array}$ & $\begin{array}{l}\text { Physiotherapist } \\
\text { (n= 382) }\end{array}$ & $\begin{array}{l}\text { Median } \\
\text { difference (p } \\
\text { value*) }\end{array}$ & $\begin{array}{l}95 \% \text { Confidence } \\
\text { intervals } \dagger\end{array}$ \\
\hline \multicolumn{5}{|l|}{ A\&E costs } \\
\hline Mean (SD) & $95.29(25.4)$ & $93.96(21.2)$ & & \\
\hline Median (IQR) & $103.68(50.8)$ & $102.40(41.4)$ & $1.23(p=0.363)$ & -1.29 to 4.06 \\
\hline \multicolumn{5}{|l|}{ Hospital care costs } \\
\hline Mean (SD) & $22.54(68.7)$ & $35.56(101.8)$ & & \\
\hline Median (IQR) & $0.0(0.0)$ & $0.0(0.0)$ & $0.0(p=0.239)$ & 0.0 to 0.0 \\
\hline \multicolumn{5}{|l|}{ Community are costs } \\
\hline $\begin{array}{l}\text { Mean (SD) } \\
\text { Median (IQR) }\end{array}$ & $\begin{array}{l}11.17(47.1) \\
0.0(0.0)\end{array}$ & $\begin{array}{l}16.52(72.7) \\
0.0(0.0)\end{array}$ & $0.0(p=0.284)$ & 0.0 to 0.0 \\
\hline \multicolumn{5}{|l|}{ Social services costs } \\
\hline Mean (SD) & $0.05(0.92)$ & $0.07(1.30)$ & & \\
\hline & $0.0(0.0)$ & \multicolumn{2}{|c|}{ Total health service cost } & 0.0 to 0.0 \\
\hline Mean (SD) & $131.23(95.6)$ & $147.81(143.9)$ & & \\
\hline $\begin{array}{l}\text { Median (IQR) } \\
\text { Personal costs }\end{array}$ & $113.13(54.9)$ & $109.44(45.3)$ & $-1.35(0.520)$ & -5.54 to 2.82 \\
\hline $\begin{array}{l}\text { Personal costs } \\
\text { Mean (SD) }\end{array}$ & \multicolumn{2}{|c|}{ Personal costs } & & \\
\hline Median (IQR) & $0.0(6.2)$ & $0.0(6.2)$ & $0.0(p=0.699)$ & 0.0 to 0.0 \\
\hline \multicolumn{5}{|l|}{ Lost production costs } \\
\hline Mean (SD) & $1516(2483)$ & $1833(2613)$ & & \\
\hline Median (IQR) & 518 (1721) & $592(2313)$ & $-74.0(p=0.403)$ & -221.9 to 74.1 \\
\hline
\end{tabular}

*Resulting from a Wilcoxon-Mann-Whitney test. †Confidence intervals for the median difference. Missing data values replaced by imputed median values.

economic sector, and from this viewpoint, this physiotherapist intervention does not look like a "best buy" for employers.

Trial physiotherapists were employed at a higher grade than may be usual for comparable work in a number of other hospitals now subject to considerable variability under the NHS modernisation initiative. If skills required could be provided by a well qualified senior 1 specialist with consultant physiotherapist support, a sensitivity analysis indicated that cost savings could be made, but there might also be an effect on practice of less experienced staff.

The mean costs within the A\&E service for the intervention were lower for the intervention group but they used more health care and had higher out of pocket costs after discharge from A\&E and so overall healthcare costs and personal costs were likely to be increased by the intervention. Personal costs were almost double in the physiotherapy arm but not significant because this was a very skew variable with most patients having zero costs. The mean cost therefore is not representative of the whole group in each arm. Median costs are zero in both arms. Lost production costs based on days lost from paid work are not different: higher costs recorded for the physiotherapist arm were largely related to provision of appliances and equipment not usually issued in a hospital context. Although confidence intervals are wide, our best estimate is that physiotherapist management is more expensive and could possibly increase health services and societal costs.

The small difference in health service costs would be predictable given the large part made up by the fixed A\&E costs. Although it may confirm what clinicians would expect, this would not necessarily predict that the difference in costs between groups would occur outside A\&E. Predicted savings within A\&E were not found because these physiotherapy salaries are not very different from junior doctors, and the physiotherapists spent more time with patients.

Physiotherapist assessment was associated with a statistically significant improvement in patient satisfaction. This is of questionable importance given the high overall satisfaction with both treatments, and it may be that patients were more likely to consent to participate if they preferred the option of physiotherapist assessment and to decline if they preferred routine care. This small difference in patient satisfaction may simply represent patient preference bias although does suggest patients will accept and endorse physiotherapists, who are legally autonomous practitioners with clinical skills applicable to A\&E.

Evaluation of aspects of the clinical effectiveness and cost effectiveness of A\&E initial assessment is an important part of modernisation. This study contributes evidence concerning a physiotherapy role. Findings show that patients in the physiotherapy arm took some days longer to return to usual activities. With hindsight, we chose the wrong outcome. Any further conclusions based on other outcomes from the study such as the value of time or EQ5D probability scores will now generate new hypotheses that need further testing in similar trials. These findings, based on data comparing randomised groups, are quite powerful indicators as such, but they are still chance observations as the trial was not designed specifically with power to show the things we have observed.

In conclusion, there is some weak evidence that physiotherapist assessment and management leads to a prolonged time before patient's return to usual activities. This study shows no clear danger from physiotherapy intervention and long term outcomes may be different. However, given these findings, our best estimate is that introducing physiotherapist assessment will increase costs to the health service and society. The most appropriate conclusion is therefore that we should continue to provide routine care, unless there is some reason why continuing with routine care is not feasible and an alternative must be found.

\section{ACKNOWLEDGEMENTS}

We should like to thank the many research participants, the physiotherapists and clinical and administrative support staff within the Norfolk and Norwich University Hospital, especially within the accident and emergency department, and also Mohammed MohseniBandpei, Jackie Coia, Elise Chohan, and Jeannette Blacklock whose involvement and support were vital to the research.

\section{Authors' affiliations}

B Richardson, F Poland, School of Allied Health Professions, University of East Anglia, Norwich, UK

L Shepstone, M Mugford, School of Medicine, Health Policy and

Practice, University of East Anglia 
B Finlayson, N Clemence, Norfolk and Norwich University Hospital Trust, Norwich

Funding: the study was funded by the NHS R\&D Eastern Region.

Conflicts of interest: none declared.

\section{REFERENCES}

1 Department of Health. Emergency care: a modernisation programme. London: Department of Health, 2001. (http://www.doh.gov.uk/emergency care/aemodernisationhtm)

2 Department of Health. Reforming emergency care. London: Department of Health, 2001.

3 Sakr M, Angus J, Perrin J, et al. Care of minor injuries by emergency nurse practitioners or junior doctors: a randomised controlled trial. Lancet 1999;354:1321-6.

4 Anderson DM, Blackwell RG, Tilley KC, et al. Use of physiotherapy in a children's casualty department. [Letter]. Med J Aust 1982;1:203.

5 Pal B, Quennell P, Hawes S. A review of accident and emergency attendances for non-traumatic musculo-skeletal complaints. Rheumatol Int 2000;19:171-5.

6 Daker-White G, Carr AJ, Harvey I, et al. Randomised controlled trial. Shifting the boundaries of doctors and physiotherapists in the orthopaedic outpatien department. J Epidemiol Community Health 2002;53:643-50.

7 Jibuike OO, Paul-Taylor G, Maulvi S, et al. Management of soft tissue knee injuries in an accident and emergency department: the effect of the introduction of a physiotherapy practitioner. Emerg Med J 2003;20:37-9.

8 Mackway-Jones K, ed. Emergency triage. London: BMJ Books, 1997.

9 Essink-Bot M-L, Krabbe P, Bonsel G, et al. An empirical comparison of four generic health status measures: the Nottingham health profile, the medical outcomes study 36-item short-form health survey, the COOP/WONCA charts, and the EuroQol instrument. Med Care 1997;35:522-37.

10 Fries JF, Spitz PW, Young DY. The dimensions of health outcomes: the health assessment questionnaire, disability and pain scales. J Rheumatol 1982;9:789-93.

11 Jensen MP, Karoly P, O'Riordan EF, et al. The subjective experience of acute pain: an assessment of the utility of ten indices. Clin J Pain 1989;5:153-9.
12 Oakley A, Rajan L, Robertson PA. Comparison of different sources of information about pregnancy and childbirth. J Biosoc Sci 1990;22:477-87.

13 Goldstein MS, Elliott SD, Guccione AA. The development of an instrument to measure satisfaction with physical therapy. Phys Ther 2000:80:853-63.

14 Mugford M, Hutton G, Fox-Rushby J, On behalf of the Steering Group for the WHO antenatal Care trial. Methods for economic evaluation alongside a multi-centre trial in developing countries: a case study from the WHO antenatal care trial. Paediatr Perinat Epidemiol 1998;12(suppl 2):75-97.

15 Cooper NJ, Mugford M, Symmons DPM, et al. Total costs and predictors of costs in individuals with early inflammatory polyarthritis: a community-based prospective study. Rheumatology 2002:41:767-74.

16 Department of Health. Pay and prices index. Financial matters May 2002 http://tap.ukwebhost.eds.com/doh/finman.nsf/Newsletters.

17 Altman DG, Machin D, Bryant TN, et al. Statistics with confidence. 2nd ed. Bristol: BMJ Books, 2000.

18 Barber J, Thomson S. How should cost data in pragmatic randomised trials be analysed? BMJ 2000;320:1197-200.

19 Griffiths P, Harris R, Richardson G, et al. Substitution of a nursing-led inpatient unit for acute services: randomised controlled trial of outcomes and costs of nursing-led intermediate care. Age Ageing 2001;30:4832-8.

20 Sakr M, Kendall R, Angus J, et al. Emergency nurse practitioners: a three part study in clinical and cost effectiveness. Emerg Med J 2003;20:158-63.

21 Brouwer W, Rutten F, Koopmanschap M. Costing in economic evaluations. In: Drummond M, McGuire A, eds. Economic evaluation in health care: merging theory with practice. Oxford: Oxford University Press/Office of Health Economics, 2001:68-93

22 Sculpher $M$. The role and estimation of productivity costs in economic evaluation. In: Drummond M, McGuire A, eds. Economic evaluation in health care: merging theory with practice. Oxford: Oxford University Press/Office of Health Economics, 2001.

23 Taimela S, Diedrich C, Hubsch $M$, et al. The role of physical exercise and inactivity in pain recurrence and absenteeism from work after active outpatient rehabilitation for recurrent or chronic low back pain, a follow up study. Spine 2000;25:1809-16. 